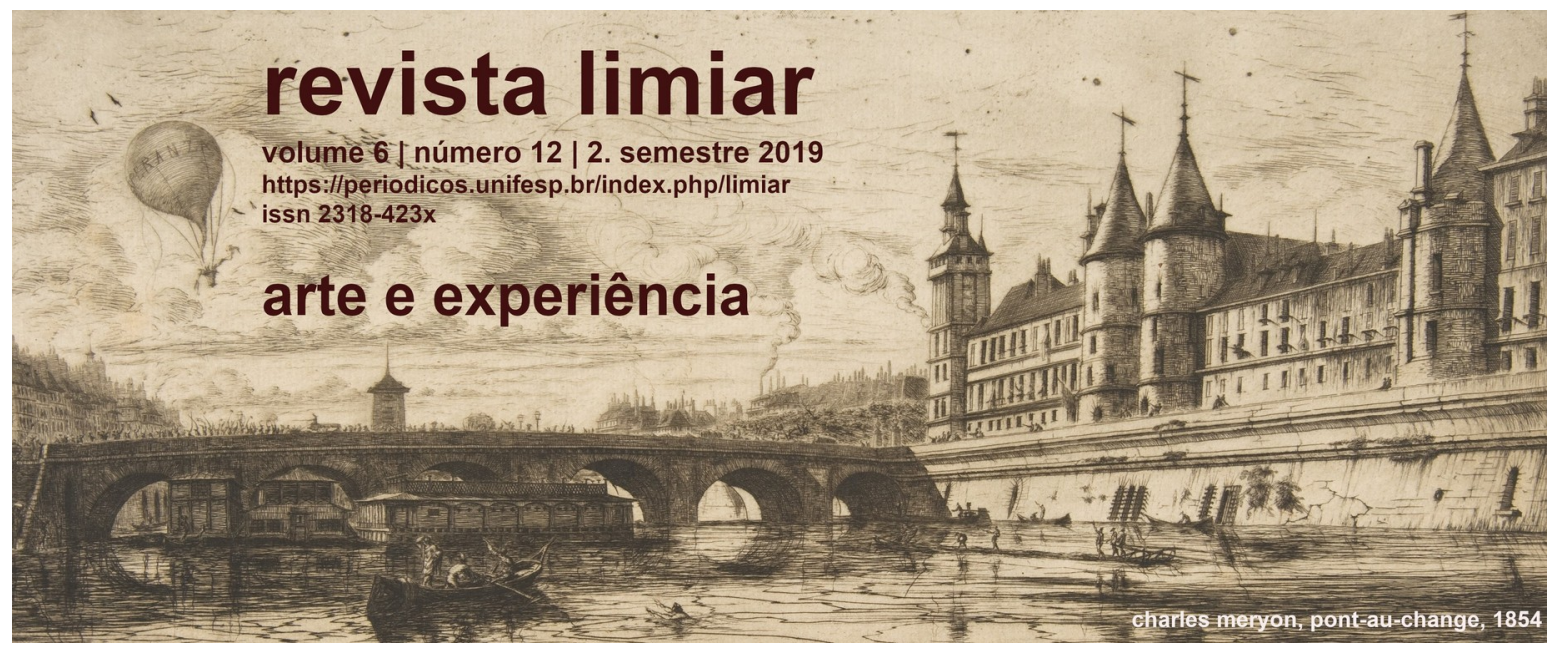

\title{
Injustiça estética
}

\section{Gustavo Hessmann Dalaqua ${ }^{1}$}

Resumo: $O$ artigo apresenta o conceito de injustiça estética, que designa qualquer dano cometido a um sujeito no que diz respeito à sua capacidade estética. A primeira seção reconstrói a noção de mentalidade colonial teorizada por Amílcar Cabral para mostrar como a injustiça estética é experimentada de maneira diferente pelos opressores e oprimidos. A segunda aborda criticamente A estética do oprimido de Augusto Boal e destaca a mútua influência existente entre injustiça estética e injustiça epistêmica. A terceira indica como os dois tipos de injustiça podem ser resistidos por meio de uma análise de outras duas obras de Boal: Teatro do oprimido e $\mathrm{O}$ arco-íris do desejo. A quarta seção conclui argumentando que a injustiça epistêmica vai contra a democracia e explicando por que um regime democrático requer justiça estética, conceito normativo segundo o qual todos os cidadãos são igualmente aptos a ter seus modos de ver e sentir os temas públicos levados em conta na deliberação política.

Palavras-chave: injustiça estética; Augusto Boal; Amílcar Cabral; injustiça epistêmica; democracia.

Abstract: This paper, which is divided into four sections, introduces the concept of esthetic injustice. Section one reconstructs Amílcar Cabral's conception of colonial

1 Professor de filosofia na Universidade Estadual do Paraná. Email: gustavodalaqua@yahoo.com.br. Versões anteriores do trabalho foram apresentadas, em 2019, no Grupo de Estudos Espinosanos (Universidade de São Paulo) e no Atelier de Théorie Critique / Critical Theory Workshop (École des Hautes Études en Sciences Sociales). Agradeço a todos os participantes destes dois grupos, em especial àqueles cujas intervenções me ajudaram a melhorar o texto: Dana Liljegren, Douglas Ferreira Barros, Gabriel Rockhill, Jennifer Ponce de León, Katerina Elvén, Lorenz Hegel, Luís César Oliva, Marilena Chaui e Samantha Bankston. 
mentality and indicates how esthetic injustice is felt differently by the oppressed and the oppressors. Section two examines Augusto Boal's A estética do oprimido and elaborates on the connection between epistemic injustice and esthetic injustice. Section three analyses Boal's $O$ arco-íris do desejo and Teatro do oprimido and shows how both types of injustice might be resisted. Section four explains why esthetic injustice is incompatible with democracy.

Keywords: esthetic injustice; Augusto Boal; Amílcar Cabral; epistemic injustice; democracy

A formação da sensibilidade é, portanto, a necessidade mais premente da época.

Friedrich Schiller, A educação estética do homem (1794)

Ismael - O caixão já vai sair! Não choras? Não tens uma lágrima?

Virgínia - Não posso! Quero, mas não consigo.

Ismael - Porque ele é preto. Preto.

Nelson Rodrigues, Anjo negro (1946)

Superioridade? Inferioridade?

Por que simplesmente não tentar sensibilizar o outro, sentir o outro?

Frantz Fanon, Peles negras, máscaras brancas (1952)

1. Injustiça estética e mentalidade colonial

$\mathrm{Na}$ ética e filosofia política contemporâneas, o número de pesquisadores que investigam a injustiça epistêmica - conceito, popularizado sobretudo a partir do trabalho seminal de Miranda Fricker, que denota "qualquer dano cometido a alguém especificamente no que diz respeito a sua capacidade enquanto ser cognitivo" - é cada vez maior. ${ }^{2}$ Nenhum desses pesquisadores, todavia, tem reservado atenção à injustiça estética, termo que cunharemos para denotar qualquer dano cometido a alguém especificamente no que concerne suas capacidades estéticas. Tal negligência afigura-se problemática porque, conforme a corrente pesquisa tentará mostrar, a injustiça epistêmica

2 FRICKER, M. Epistemic Injustice. Oxford: Oxford University Press, 2007, p. 1. Para uma boa amostragem de filósofos contemporâneos que estudam injustiça epistêmica, ver, por exemplo, KIDD, I. J.; MEDINA, J.; POHLHAUS, G. (Eds.) The Routledge Handbook of Epistemic Injustice. Londres: Routledge, 2017. 
e a injustiça estética reforçam-se mutuamente. Sendo assim, quem deseja compreender plenamente o modo de reprodução desta há de investigar aquela.

Por capacidades estéticas, designamos nossas capacidades de sentir e imaginar algo. Ambas capacidades podem ser chamadas de estéticas na medida em que a "estética" remete ao campo do sentido e do imaginado. No grego antigo, "aiesthétós" significava "perceptível pelos sentidos". ${ }^{3}$ A estética denota um tipo de percepção que é moldado por nossa sensibilidade e que informa nosso conhecimento. Como destacaremos na próxima seção, nossas capacidades estéticas são essenciais para nossos pensamentos e conhecimentos - i.e., são essenciais para nossas capacidades epistêmicas.

Tal qual a injustiça epistêmica, a injustiça estética relaciona-se de maneira íntima à opressão, prática social que se exerce, inter alia, por meio da postulação de hierarquias sociais. Enquanto processo de diferenciação social que classifica os cidadãos em "inferiores" e "superiores", a hierarquização compreende: i) a postulação de diferenças entre oprimido (inferior) e opressor (superior); ii) a valorização dessas diferenças em proveito do opressor; iii) a absolutização dessas diferenças como atributos imutáveis que justificam a posição subalterna dos grupos oprimidos perante os opressores. Estes três processos põem em relevo o poder "construtivo" da opressão. Como explicaremos em breve, a opressão é um poder não apenas repressor como produtor. Ao conjurar a oposição "nós" vs. "eles", a opressão funciona como uma cola que produz identidades políticas salientes. ${ }^{4}$

Assim como a opressão em geral, a injustiça estética é um conceito relacional que afeta tanto aqueles que, por conta dela, veem-se socialmente elevados quanto aqueles que, inversamente, veem-se socialmente diminuídos. Apesar de prejudicial às capacidades estéticas de ambos, a injustiça estética gera efeitos diversos nos opressores e nos oprimidos. Ao passo que o entorpecimento afetivo provocado pela injustiça estética aumenta a autoestima dos opressores, nos oprimidos a injustiça estética tende a diminuir

3 BOAL, A. A estética do oprimido. Rio de Janeiro: Garamond, 2009, p. 25.

$4 \mathrm{Em}$ um de seus últimos livros, Toni Morrison põe em relevo este aspecto da opressão ao mostrar que identidades políticas como "branco" e "negro" são construtos históricos resultantes do exercício da opressão. Ver MORRISON, T. The Origin of Others. Cambridge, MA: Harvard University Press, 2017, p. 5-6, 15-6, 48-9. Sobre o poder que a opressão tem para criar identidades coletivas, cf. FREIRE, P. Pedagogia do oprimido. Rio de Janeiro: Paz e Terra, 1974, cap. 1 e YOUNG, I. M. Justice and the Politics of Difference. Princeton, NJ: Princeton University Press, 1990, cap. 2. 
a autoestima. A fim de ilustrar esse ponto, vamos comparar os diferentes modos pelos quais a injustiça estética repercute no âmbito psíquico dos oprimidos e opressores por meio de uma análise daquilo que os teóricos anticoloniais chamam de mentalidade colonial.

A expressão "mentalidade colonial" possui duplo sentido. Em sentido literal, significa a mentalidade que um Estado colonial impõe aos colonizados no intuito de legitimar o colonialismo. A mentalidade colonial designa os afetos e crenças, incrustados na mente das pessoas, que são favoráveis à opressão colonial. Trata-se do reflexo psicológico da opressão colonial que, de um lado, torna os colonizados mais dóceis e, de outro, deixa os colonizadores mais à vontade no seu papel de opressores. Em um sentido menos literal, o termo designa um enquadramento mental opressivo que hierarquiza as pessoas em grupos "superiores" e "inferiores". Nesse sentido, a mentalidade colonial pode ser usada para denotar a opressão presente em sociedades pós-coloniais, vale dizer, sociedades que do ponto de vista político são formalmente independentes e autônomas. Outrossim, pode ser usada para denotar a opressão interna sofrida por grupos socialmente subalternizados no interior de um próprio país.

O primeiro sentido da mentalidade colonial é o que aparece em Return to the Source: Selected Speeches by Amilcar Cabral, coletânea publicada por um grupo de acadêmicos e ativistas africanos e afrodescendentes alguns meses após o assassinato de Cabral. ${ }^{5}$ Um dos líderes anticoloniais mais proeminentes da África, Cabral entendia que o colonialismo europeu perpetuava-se não só por vias materiais como também por uma certa "mentalidade", um modo epistêmico e afetivo de se relacionar com o mundo que fora forjado pelos colonizadores europeus no afã de justificar o colonialismo. ${ }^{6}$ Tal mentalidade - que legitimava a opressão colonial com o argumento de que os colonizadores eram "superiores" e os colonizados "inferiores" - produzia, ao ser adotada pelos colonizados, o que Cabral chamava de "alienação cultural". ${ }^{7}$

5 Examinaremos o segundo sentido da mentalidade colonial ao analisar a obra Os meus romanos de Ina von Binzer. Embora não chegue a usar a expressão, é possível afirmar que Boal tematiza o que aqui chamamos de mentalidade colonial quando discorre sobre o colonialismo cultural, termo que usa para descrever "a imposição dos valores culturais de um país sobre outro". Cf. BOAL, A. Técnicas latino-americanas de teatro popular. São Paulo: Hucitec, 1984, p. 96.

6 CABRAL, A. Return to the Source. Nova York: Monthly Review Press, 1973, p. 43.

7 lbid., p. 45. 
A alienação cultural é um processo que ocorre quando membros de um grupo oprimido insistem em se afastar de sua cultura, o que inclui suas tradições, instituições, história, arte, idioma, conhecimento local etc. Enquanto manifestação da mentalidade colonial, a alienação cultural provoca entorpecimento estético e epistêmico. Ou seja, ela faz com que os oprimidos se tornem desinteressados e indiferentes à arte e ao conhecimento produzidos por seus semelhantes, o que por seu turno atravanca o desenvolvimento de suas capacidades cognitivas e estéticas. Daí que, conforme aponta um comentador, Cabral identificasse a mentalidade colonial e a opressão dela resultante com a atrofia "da criatividade da cognição". ${ }^{8}$

Cabral estabelece que, além de expulsar os colonizadores europeus, a luta dos africanos por liberdade reclama resistir à alienação cultural. Ao promover semelhante resistência - denominada por Cabral de "retorno à fonte" -, os africanos cessam de ser cúmplices da opressão e mentalidade coloniais. ${ }^{9}$ Somente assim é que eles conseguem superar o "complexo de frustração" e baixa autoestima que o cultivo da mentalidade colonial neles provoca. ${ }^{10}$

Quando se encontram sob o jugo da mentalidade colonial, membros de grupos oprimidos se recusam a engajar com a própria cultura e tentam, a todo custo, emular as práticas culturais dos colonizadores. Não tarda, contudo, para que os oprimidos compreendam que, não importa o quão arduamente se esforcem para parecer com o senhor branco, eles nunca serão considerados seu semelhante. Por mais que aprenda a falar o idioma do branco corretamente e erradique de si quaisquer traços que denunciem sua origem africana, o africano não demora a perceber que jamais superará a fronteira discriminatória que, em um mesmo movimento, alça o opressor ao posto de "superior" e o relega a um status social "inferior". Mesmo que mimetize à exaustão os hábitos dos "superiores", o africano está fadado a ser um "marginal" nos moldes da visão de mundo

8 GIBSON, N. C. "No easy victories: some reflections on Amilcar Cabral's legacy", p. 27. A respeito da importância da abertura epistêmica na teoria crítica cabralina, cf. CABRAL, A. A prática revolucionária: unidade e luta II. Lisboa: Seara Nova, 1977, p. 161-63; RABAKA, R. Africana Critical Theory. Lanham, MD: Lexington Books, 2009, p. 271 e Concepts of Cabralism: Amilcar Cabral and Africana Critical Theory. Lanham, MD: Lexington Books, 2014, p. 301; SANTOS, B. S. O fim do império cognitivo: a afirmação das epistemologias do Sul. Belo Horizonte: Autêntica, 2019, p. 115-17. Sobre o modo como a mentalidade colonial atrofia o desenvolvimento das capacidades dos colonizados, ver BHARGAVA, R. "Overcoming the epistemic injustice of colonialism" e MEMMI, A. Retrato do colonizado precedido pelo retrato do colonizador. Rio de Janeiro: Paz e Terra, 1967, p. 28, 83.

9 CABRAL, A. Return to the Source, Op. cit., p. 59.

10 Ibid., p. 62. 
colonialista. ${ }^{11}$ De acordo com a mentalidade colonial, é justamente porque são inferiores que os africanos dão tudo de si para parecer com os europeus. Assim, quanto mais tenta se parecer com o opressor branco, mais o africano confirma seu caráter subalterno. Em síntese, a internalização da mentalidade colonial pelos colonizados os inferioriza e, conforme Cabral mostra, os imbui de sentimentos de inferioridade intelectual, uma avaliação depreciativa de suas qualidades cognitivas que os levam a superestimar as capacidades epistêmicas e estéticas do opressor e a aceitar acriticamente o discurso dominante.

No que diz respeito ao opressor, os efeitos contrários são observados. Ao passo que diminui a autoconfiança dos oprimidos, nos opressores a injustiça estética exacerba a autoestima. A injustiça estética limita o desenvolvimento das capacidades estéticas e epistêmicas tanto do opressor quanto do oprimido, mas o faz de maneiras distintas. Tomemos como exemplo o livro Os meus romanos: alegrias e tristezas de uma educadora alemã no Brasil. Esta coleção de cartas do século XIX, escritas por Ina von Binzer no período em que residiu no Brasil, é útil para os nossos propósitos, pois evidencia como a mentalidade colonial e sua concomitante injustiça estética aumentam a autoestima do opressor. A mentalidade colonial de Binzer, cabe apontar, pertence ao segundo sentido do termo delineado no início desta seção. As cartas da educadora, de fato, revelam que Binzer insistia em abordar a cultura brasileira por meio de um enquadramento mental opressor, segundo o qual os grupos étnicos europeus eram "superiores", e os latino-americanos, "inferiores".

A mentalidade colonial de Binzer a impedia de apreciar a arte feita por latinoamericanos, ao mesmo tempo em que reforçava seu orgulho e senso de superioridade por ser branca. Em carta endereçada à Grete, irmã da autora que morava na Alemanha, Binzer reconhece ser incapaz de conferir valor às práticas culturais dos "latinos":

Depois, sentou-se ao piano uma senhora muito calma, muito gorda, de olhos muito escuros que começou a tocar [...]. Haviam-me dito que ela tocava com perfeição e por isso escutei-a atentamente. Ach! Grete! Serei tão inflexivelmente germânica que não possa achar esses latinos espirituosos ou interessantes? Mas não consegui sentir de outro modo e, a mim, nada me diziam esses dedos [...], aquele rosto impassível cor de cera amarelada, os olhos pretos que pareciam borrões de tinta [...] não consegui entusiasmar-me e olhava medrosa, em volta de mim, com

11 lbidem. 
receio de que o percebessem. Todos os rostos estavam pálidos, amarelados, e de tanta admiração por aquela "impecável" execução imóveis, todos menos um. Desde há alguns dias, acha-se em visita em nossa casa um jovem arquiteto italiano [...]; esse infeliz parecia sentir a mesma coisa que eu. Sem querer, sorri, olhando para ele, pois nossa comum sensibilidade europeia nos fazia vibrar de maneira idêntica em relação às condições daqui; com uma expressão infinitamente cômica, ele levantou os olhos para o teto. ${ }^{12}$

Ao longo das cartas, torna-se claro para o leitor que o cultivo de uma mentalidade colonial da parte de Binzer é o que a impossibilita de apreciar a música feita pelos latinos. Com efeito, em carta enviada a Grete um mês depois, Binzer descreve a música tocada pelos "pobres negros" nas ruas do Rio de Janeiro como "ensurdecedora" e "insípida". ${ }^{13}$ Binzer nega à arte dos afro-brasileiros o título de "música" porque, de acordo com seus padrões europeus, os barulhos que faziam não eram senão "o mais desarmonioso dos sons". ${ }^{14} \mathrm{Na}$ carta seguinte endereçada à Grete, Binzer continua com sua crítica aos afrobrasileiros e sugere que eles estão condenados a não desenvolver uma cultura própria:

Se, segundo o princípio sustentado por um famoso professor de Berlim, todo homem culto procura viver recolhido em sua casa, chegaremos à conclusão que, em matéria de cultura, nos encontramos aqui em condições idênticas às de Abraão em relação aos justos, em Sodoma. Os pretos desocupados não se encontram senão na porta da rua fumando e cuspindo. ${ }^{15}$

De acordo com a mentalidade colonial de Binzer, os afro-brasileiros não podem alcançar o estatuto de "homens de cultura", pois o termo "cultura" possui sentido unívoco e encontra na Europa seu único exemplar possível. Visto que os afro-brasileiros são gregários e estão sempre socializando na rua, eles não satisfazem o princípio, identificado por um famoso professor berlinense, constitutivo de toda "cultura". Por conseguinte segue tal linha de raciocínio -, os afro-brasileiros carecem de "cultura".

Particularmente interessante aos nossos propósitos é o modo como a inabilidade de Binzer para apreciar a arte feita por afro-brasileiros (e latino-americanos no geral) revigora sua autoestima. É justamente por ser de um grupo étnico "superior" que Binzer não consegue compreender as práticas culturais feitas pelos "latinos" inferiores. Binzer

12 BINZER, I. Os meus romanos: alegrias e tristezas de uma educadora alemã no Brasil. Rio de Janeiro: Paz e Terra, 1994, p. 29.

13 lbid., p. 39.

14 Ibidem.

15 lbid., p. 66. 
decerto sofre de injustiça estética, haja vista sua mentalidade colonial danificar sua capacidade de sentir os fenômenos estéticos que a circundam e atrofiar o desenvolvimento de sua sensibilidade. Todavia, Binzer quase nunca revela-se frustrada com sua incapacidade de apreender as práticas artísticas que vê no Brasil. Pelo contrário, sempre que se depara com uma injustiça estética, Binzer insiste em reforçar sua crença na superioridade europeia. Daí os diferentes modos em que a injustiça estética repercute na psique do oprimido e do opressor: ao passo que nos socialmente privilegiados a injustiça estética tende a aumentar o brio e a autoestima, nos oprimidos, tende a diminuílos.

2. A mútua influência entre injustiça estética e injustiça epistêmica

Tendo delineado os diferentes modos pelos quais a injustiça estética se manifesta, passemos em revista a mútua influência existente entre injustiça estética e injustiça epistêmica. Para tanto, examinemos o livro $A$ estética do oprimido de Augusto Boal. Publicado logo após a morte do autor, A estética do oprimido parte da tese de que a opressão muda a forma como as pessoas sentem as coisas. Quer dizer, a opressão se perpetua não apenas por meios materiais como também por uma constelação de afetos e crenças, internalizada pelos oprimidos, que os torna cúmplices da opressão que se lhes acomete. Boal estabelece que "uma opressão, seja de que tipo for, só ocorre porque, em maior ou menor medida, conta com a aceitação da vítima. [...] Oprimem-nos porque estamos dispostos a fazer concessões". ${ }^{16}$ A opressão é um exercício de poder tanto repressivo quanto produtivo: ao levar o oprimido a internalizar certas normas, ela produz uma série de crenças e comportamentos, ao mesmo tempo em que reprime e constrange o livre desenvolvimento das capacidades epistêmicas e estéticas.

Boal explica no começo da Estética do oprimido que a opressão

introduz simbólicas cercas de arame farpado nas cabeças oprimidas, embalsamando o pensamento e criando zonas proibidas à inteligência. Abre canais sensíveis por onde inocula a obediência não contestatória, impõe códigos, rituais, modas, comportamentos [...] políticos e sociais que perpetuam a vassalagem. ${ }^{17}$

16 BOAL, A. 200 exercícios e jogos para o ator e o não-ator com vontade de dizer algo através do teatro. Rio de Janeiro: Civilização Brasileira, 1999a, p. 289.

17 BOAL, A. A estética do oprimido, Op. cit., p. 17-8. Esse trecho parece ser ignorado por Tony Fisher ("Radical democratic theatre", p. 21). Segundo Fisher, Boal pensava que a opressão não alterava a 
Valendo-se de uma expressão freireana, Boal afirma que a opressão perpetua-se por meio de "cercas de arame farpado" incrustadas nas cabeças dos oprimidos. ${ }^{18}$ Tais cercas podem ser associadas com a injustiça estética na medida em que anestesiam as capacidades estéticas, atrofiando, pois, a percepção estética dos oprimidos e tornandoIhes difícil diagnosticar a opressão que sofrem. Destarte, a injustiça estética confina os oprimidos à obediência não contestatória e aborta o desenvolvimento de qualquer crítica. Mais ainda, ela manipula a sensibilidade afetiva dos oprimidos de modo a entorpecê-los a outros tipos de arte, produzindo o que chamamos acima de entorpecimento afetivo. Ao camuflar a opressão, a injustiça estética limita a imaginação dos oprimidos e esmorece suas capacidades críticas.

A estética do oprimido mostra que a injustiça estética relaciona-se de maneira íntima com a injustiça epistêmica. Quando a arte, a cultura e as demais práticas artísticas são manipuladas pelos opressores com o intuito de garantir que a percepção dos oprimidos seja estrategicamente limitada, as capacidades epistêmicas destes também são danificadas. Injustiça estética e injustiça epistêmica reforçam-se mutuamente, pois a percepção estética também contém propriedades epistêmicas. Tal qual define Boal, a estética é o domínio do "conhecimento sensível" e designa a percepção resultante tanto dos sentidos quanto da inteligência. ${ }^{19}$ Recusando a separação clássica entre noética (domínio da inteligência) e estética (domínio do sensível) e a dicotomia razão vs. emoção, Boal sustenta que "a sensibilidade é também atividade cognitiva". ${ }^{20}$ Nossa percepção estética informa o conhecimento que temos dos fenômenos circundantes. Portanto, um

subjetividade do oprimido e, ademais, entendia que a luta contra a opressão consistiria em "recuperar" uma espécie de subjetividade originária que teria sido camuflada pelos discursos opressores (Ibidem). O que Boal indica na passagem em recuo acima, contudo, é que a opressão altera o próprio modo de funcionamento da subjetividade e da mentalidade dos oprimidos. Nesse sentido, longe de exigir a recuperação de uma subjetividade originária, o que a luta contra opressão exige é a criação de uma nova subjetividade.

18 FREIRE, P. Cartas a Cristina. Rio de Janeiro: Paz e Terra, 1994, p. 153. Sobre a influência de Freire em Boal, cf. BOAL, A. A estética do oprimido, Op. cit., p. 145; MUTNICK, D. "Critical interventions"; PATERSON, D. "Putting the 'pro' in protagonist"; SCHECHNER, R. e CHATTERJEE, S. "Augusto Boal", p. 89-90; VITTORIA, P. "Paulo Freire and Augusto Boal". No ensaio que dedica a Freire, Boal tematiza sua compreensão da liberdade como isegoria quando relaciona a opressão e a ausência de liberdade com a inexistência do poder equânime dos cidadãos para falar em público. Cf. BOAL, A. Aqui ninguém é burro, p. 103. Retomaremos esse aspecto do pensamento boalino adiante.

19 BOAL, A. Estética do oprimido, Op. cit., p. 26.

20 lbid., p. 83.

limiar | volume 6 | número 12 | 2. semestre 2019 |109 
indivíduo está fadado a experimentar injustiça epistêmica sempre que suas capacidades estéticas forem lesadas.

Nossas capacidades de conhecer, julgar e pensar dependem de nossos sentidos. Por isso mesmo, Boal entende que a regulação do campo estético é crucial para a manutenção de um regime opressor. Para compreender esse ponto, tomemos como exemplo o "capitalismo neoliberal", que no livro de Boal é identificado como uma grande fonte de injustiça estética e, por conseguinte, de opressão. ${ }^{21}$ Ao tornar o individualismo competitivo lógica última de explicação para todos os comportamentos humanos, a estética anestésica neoliberal torna-nos custoso sentir afetos não competitivoindividualistas. Ela nos estimula a cultivar apenas aspectos de nossa afetividade que a convém, limitando nossa percepção do mundo de modo a tornar inimaginável qualquer organização social que não a calcada no individualismo competitivo.

A resistência contra a injustiça estética requer que aprendamos a "ver aquilo que olhamos". ${ }^{22}$ A injustiça estética distorce nossa percepção de modo a nos fazer aceitar a opressão como algo natural. Quando, por exemplo, vemos um sem-teto dormindo na rua em uma noite fria que poderá matá-lo de hipotermia, o que enxergamos é, na verdade, um ser humano. Os discursos opressores que estruturam nossa sociedade e que nos moldam, contudo, facilmente nos levam a agir como se o sem-teto fosse invisível ou inumano.

Os modos pelos quais apreendemos - ou ainda, pelos quais deixamos de apreender - os eventos político-sociais determinam nossas opiniões políticas. Uma parte significativa de nossas ações e reações morais se formula por meio de enquadramentos estéticos e epistêmicos construídos socialmente. ${ }^{23}$ Estes enquadramentos condicionam e moldam nossos sentimentos e conhecimento do mundo. Eles discriminam as vidas "superiores" das "inferiores", sobretudo, por meio de nossos sentidos e cognição. Uma vez que suas sensibilidade e cognição sejam manipuladas de determinada forma, os indivíduos passam a apreender o mundo, seletivamente, de modo a favorecer os poderes opressores em operação. Urge-se, portanto, travar uma luta contra as forças opressoras

21 lbid., p. 140.

22 BOAL, A. Jogos para atores e não-atores. Rio de Janeiro: Civilização Brasileira, 1999b, p. 172.

23 Enquadramentos estéticos e epistêmicos são sistemas de significados coletiva e historicamente produzidos por meios dos quais um grupo percebe, compreende e avalia sua vida individual e coletiva. 
que visam modelar nossos afetos e conhecimento de modo a nos tornar coniventes com a opressão.

3. Resistindo a injustiça estética e a epistêmica na prática

$\mathrm{Na}$ medida em que se reforçam mutuamente, a injustiça estética e a epistêmica devem ser resistidas conjuntamente. A retroalimentação existente entre ambos os eixos de opressão torna improvável que qualquer um deles consiga ser combatido efetivamente sem que o outro também o seja. Boal sabia que a resistência contra a injustiça é uma tarefa tanto intelectual quanto afetiva, e foi justamente por isso que inventou o teatro do oprimido e a técnica do arco-íris do desejo. Ao passo que aquele tem por foco a opressão corporal provocada pela injustiça estética e epistêmica, esta visa resistir a manipulação e a limitação dos desejos e imaginação dos oprimidos que ambos os tipos de injustiça causam.

Compilação de ensaios escritos entre 1962 e 1973, Teatro do oprimido e outras poéticas políticas é um livro que usa o teatro como arma contra a opressão e em prol da liberdade:

a primeira palavra do vocabulário teatral é o corpo humano, principal fonte de som e movimento. Por isso, para que se possa dominar os meios de produção teatral, deve-se primeiramente conhecer o próprio corpo, para poder depois torná-lo mais expressivo. Só depois de conhecer o próprio corpo e ser capaz de torná-lo mais expressivo, o "espectador" estará habilitado a praticar formas teatrais que, por etapas, ajudem-no a liberar-se de sua condição de "espectador" e assumir a de "ator", deixando de ser objeto e passando a ser sujeito, convertendo-se de testemunha em protagonista. [...] Existe uma enorme quantidade de exercícios que se podem praticar, tendo todos, como primeiro objetivo, fazer com que 0 participante se torne cada vez mais consciente do seu corpo, de suas possibilidades corporais, e das deformações que o seu corpo sofre devido ao tipo de trabalho que realiza. Isto é: cada um deve sentir a "alienação muscular". ${ }^{24}$

24 BOAL, A. Teatro do oprimido e outras poéticas políticas. Rio de Janeiro: Civilização Brasileira, 2005, p. 188-90. 
O teatro do oprimido põe em relevo o fato de que nossos corpos são oprimidos. ${ }^{25}$ Nossos papeis de gênero, o trabalho que realizamos, os meios de transporte que usamos, o tipo de cidade em que vivemos - tudo isso de um modo ou de outro serve de vetor da opressão na medida em que, promovendo a injustiça estética e a epistêmica, coage nossa capacidade de sentir e conhecer nossos corpos. Uma trabalhadora cujo desenvolvimento muscular é atrofiado porque ela é obrigada a permanecer na mesma posição quase o dia inteiro é uma vítima de injustiça estética. O estiramento muscular encurtado não resulta de uma falha idiossincrática dela. Antes, constitui uma "deformação social" - social no sentido de que é provocada por processos sociais que fogem ao controle da trabalhadora. ${ }^{26}$

O primeiro estágio na luta pela libertação orquestrada pelo teatro do oprimido consiste em denunciar que vários de nossos movimentos supostamente "espontâneos" são, em verdade, deformações coercitivas advindas do "conjunto de papeis que uma pessoa desempenha na realidade". ${ }^{27}$ A primeira etapa do teatro do oprimido é principalmente desconstrutiva, pois tem "por finalidade 'desfazer' as estruturas musculares dos participantes. Isto é: desmontá-las, verificá-las, analisá-las” de maneira que "se tornem conscientes. Para que cada operário, cada camponês, compreenda, veja e sinta até que ponto seu corpo está determinado pelo seu trabalho" ${ }^{28}$

Embora necessária, a desconstrução não é um objetivo em si mesmo; à etapa desconstrutiva, deve-se seguir outra construtiva na qual os cidadãos são encorajados a experimentar seus corpos de um novo jeito e construir novos movimentos. Para Boal, essa segunda etapa depende da primeira, pois o primeiro passo para resistir a opressão e arquitetar maneiras mais livres de conduzir nossos corpos é tomar ciência de que a

25 Como observa Phillip Auslander ("Boal, Blau, Brecht: the body”, p. 124), uma das principais teses do teatro do oprimido é a de que o corpo humano é "o lócus primário das sedimentações ideológicas" produzidas por práticas sociais opressivas. De acordo com Boal, "a vida material do corpo expressa a opressão porque o próprio corpo, seus gestos e ações são determinados por relações ideológicas" (Ibid., p. 129; ver também HOWE, K. "Constraints and possibilities in the flesh: the body in theatre of the oppressed", p. 76). Com efeito, a injustiça estética e a epistêmica podem ser associadas com o conceito de "ideologia", definido por Boal como "ideias recebidas sensorialmente pelos cidadãos, que sequer passam pelas suas consciências, mas determinam comportamentos: maneiras de falar, de agir, de pensar" ( $A$ estética do oprimido, Op. cit., p. 211). A respeito da relação entre injustiça epistêmica e o conceito marxiano de ideologia, ver MILLS, C. W. "Ideology". Sobre o modo como a ideologia fomenta o fenômeno que aqui chamamos de injustiça estética, cf. DE LEÓN, J. P. e ROCKHILL, G. "Toward a compositional model of ideology".

26 BOAL, A. Teatro do oprimido e outras poéticas políticas, Op. cit., p. 188.

27 Ibid., p. 191.

28 lbid., p. 191-92. 
opressão existe. Afinal, se os oprimidos creem que suas deformações corporais não passam de falhas idiossincráticas causadas por hábitos meramente individuais, eles nunca agirão em conjunto a fim de resistir à opressão. Assim como a estética do oprimido em geral, o teatro do oprimido busca sublinhar que as relações de poder podem ser resistidas e alteradas. ${ }^{29}$ Com isso, exorta os oprimidos à revolta: "Tudo está sujeito à crítica, à retificação. Tudo é transformável". ${ }^{30}$

Enquanto o Teatro do oprimido revela como a opressão constrange nosso conhecimento corporal, $O$ arco-íris do desejo lida com outra forma de injustiça epistêmica, forma esta que manipula a estrutura psíquica dos oprimidos e prejudica sua capacidade de conhecer a si mesmos e sua capacidade estética de imaginar diferentes objetos de desejo. Publicado originalmente em 1990, O arco-íris do desejo introduz a metáfora do "tira na cabeça", conceito tão central aos argumentos do livro que Boal inicialmente cogitara usá-lo como título. Na "Introdução", Boal explica que o arco-íris do desejo foi uma técnica que criou, nos anos setenta, quando fora exilado na França. ${ }^{31}$

Recém-saído de uma ditadura militar onde a violência policial era comum, Boal se surpreendeu quando vários franceses declararam se sentir oprimidos. "Era como se eu, involuntariamente, estivesse sempre perguntando: 'Sim, mas onde está a polícia?' Porque eu estava habituado a trabalhar com opressões concretas e visíveis". ${ }^{32}$ A surpresa o levou a perceber que a estética do oprimido deveria levar em conta não só os aspectos corporais da opressão como também os psicológicos. ${ }^{33} \mathrm{~A}$ vivência de Boal na França dos anos setenta o fez entender que o poder opressor consegue assumir várias formas, sendo que a polícia e demais aparatos estatais constituem apenas um dentre vários vetores de sua transmissão. Como Foucault afirmava mais ou menos na mesma época, o poder não

29 Utilizamos por vezes a expressão "estética do oprimido" para nos referir não só ao livro $A$ estética do oprimido como também às demais obras de Boal sobre estética e opressão. A ressalva é digna de nota porque alguns comentadores de Boal usam "estética do oprimido" para se referir apenas aos argumentos apresentados no livro homônimo.

30 BOAL, A. Teatro do oprimido e outras poéticas políticas, Op. cit., p. 203.

31 BOAL, A. O arco-íris do desejo. Rio de Janeiro: Editora Record, 1996, p. 23.

32 lbid., p. 23.

33 Sobre a diferença entre opressão corporal e psicológica, ver BARTKY, S. L. Femininity and Domination: Studies in the Phenomenology of Oppression. Londres: Routledge, 1990, cap. 2 e CUDD, A. E. Analyzing Oppression. Oxford: Oxford University Press, 2006. Para uma análise detalhada sobre a opressão psicológica, ver RATNER, C. "Psychology of oppression". 
é apenas repressivo, mas também produtivo. ${ }^{34} \mathrm{O}$ poder opressivo produz certos comportamentos ao fazer com que as pessoas internalizem certas normas de conduta:

em Paris, fiz um longo atelier que durou dois anos, intitulado Le Flic dans la Tête (O Tira na Cabeça). Eu partia desta hipótese: o tira está na cabeça, mas os quarteis estão do lado de fora. Tratava-se de tentar descobrir como lá penetraram e inventar os meios de fazê-los sair. ${ }^{35}$

O arco-íris do desejo é uma técnica estética que investiga como a multiplicidade "caleidoscópica" da imaginação e do desejo humanos foi empobrecida por conta de opressões internalizadas por grupos sociais subalternizados. ${ }^{36}$ Seu pressuposto é o de que "as opressões que se exercem na realidade social refletem-se na subjetividade do sujeito, são internalizadas e passam a fazer parte dela. Podemos carregar em nós nossos próprios opressores". ${ }^{37}$ Essas opressões internalizadas, que cerceiam o livre desenvolvimento da cognição, dos afetos e da imaginação dos cidadãos, correspondem ao que Boal chama de "tira na cabeça". ${ }^{38}$

O arco-íris do desejo "possui propriedades gnosiológicas, isto é, propriedades que estimulam o saber e o descobrir, o conhecimento e o reconhecimento". ${ }^{39}$ Ele permite aos oprimidos diagnosticar a injustiça a que são submetidos ao mostrar-lhes que o enquadramento epistêmico e estético que usam para estruturar seus desejos é uma fonte de opressão. A capacidade dos oprimidos para conhecer e sentir seus desejos foi, de maneira análoga à capacidade deles para se conhecer em geral, tolhida por poderes que costumavam ser apenas externos, mas que agora tornaram-se parte de sua própria psique. Após perceberem que encontram-se sob o jugo da injustiça estética e epistêmica - uma situação que clama por resistência -, os oprimidos ganham a oportunidade de formular seus desejos de maneira autônoma.

34 FOUCAULT, M. Histoire de la sexualité, vol. 1. Para uma análise comparativa entre Foucault e a estética do oprimido boalina, cf. LEAL, D. Pedagogia e estética do teatro do oprimido. São Paulo: Hucitec, 2015, cap. 2.

35 BOAL, A. O arco-íris do desejo, Op. cit., p. 23.

36 Ibid., p. 115.

37 BOAL, A estética do oprimido, Op. cit., p. 236.

38 BOAL, A. e EPSTEIN, S. "The cop in the head", p. 35.

39 BOAL, A. O arco-íris do desejo, Op. cit., p. 34.

limiar | volume 6 | número 12 | 2. semestre 2019 |114 
O itálico na frase anterior serve para destacar que a mera tomada de consciência de que há injustiça epistêmica não basta para superá-la. Tomemos como exemplo a homofobia internalizada, um caso exemplar de como a injustiça epistêmica consegue estorvar o desenvolvimento de si. $^{40}$ Ainda que a homofobia não seja um tema presente em O arco-íris do desejo, não é difícil entender por que a técnica de Boal foi apropriada por ativistas LGBTQ. A razão pela qual minorias sexuais costumam levar mais tempo para explorar confortavelmente suas vidas afetivas é que na maior parte das sociedades, se não em todas, todos são treinados desde cedo a adotar um quadro estético e epistêmico heteronormativo. Aqueles que não são heterossexuais, portanto, encontram-se em desvantagem, pois carecem de recursos hermenêuticos para compreender seus desejos e imaginar diferentes maneiras de realizá-los.

O arco-íris do desejo ajuda minorias sexuais a se conhecer e a explorar plenamente seus desejos e afetos. Conforme aponta Helen Sarapeck, pesquisadora que utiliza a estética do oprimido boalina, o arco-íris do desejo possibilita que minorias sexuais lutem contra a injustiça estético-epistêmica na medida em que confrontam o tira em suas cabeças, franqueando-lhes, pois, "a descoberta de si mesmo". ${ }^{41}$ Todavia, como o testemunho de Sarapeck evidencia, a resistência à injustiça epistêmica, no caso da homofobia internalizada, é extremamente difícil. Mesmo quando percebem que seus desejos foram manipulados por um enquadramento mental heteronormativo que os oprime, alguns homossexuais não conseguem resistir à homofobia. Como exemplo, Sarapeck relata um caso que observou quando trabalhou junto com o GHOTA (Grupo Homossexual de Teatro do Oprimido), uma companhia teatral carioca composta majoritariamente por homens gays de baixa renda que usam o arco-íris do desejo para resistir à homofobia.

Para lutar contra o tira na cabeça, a técnica do arco-íris do desejo busca primeiro delinear o mecanismo psicológico por meio do qual a opressão é internalizada pelo oprimido, denominado por Boal de "osmose". ${ }^{42}$ Como o nome já indica, a osmose é uma reação psicológica quase que automática de qualquer um que vive em uma sociedade opressora - isto é, em uma sociedade em que nem todos os grupos sociais são tratados

40 FRICKER, M. Epistemic Injustice, Op. cit., p. 163-64.

41 SARAPECK, H. "A descoberta de si mesmo", p. 37.

42 BOAL, A. O arco-íris do desejo, Op. cit., p. 54.

limiar | volume 6 | número 12 | 2. semestre 2019 | 115 
de maneira equânime porque alguns são hierarquizados como "superiores" a outros. A osmose se produz "em toda parte, em todas as células da vida social". ${ }^{43}$ Não obstante, diferentes tipos de opressões proliferam em diferentes âmbitos sociais. Ciente disto, a técnica boalina convida os oprimidos a revisitar o passado de modo a delinear os lugares e as ocasiões em que um certo tipo de osmose ocorreu entre eles.

No período em que trabalhou com o GHOTA, Sarepeck observou que a maior parte dos homens gays nomeava a família, a igreja e o local de trabalho como campos férteis para a osmose da homofobia. Após traçar a gênese histórica da osmose que infiltrou em suas cabeças o tira homofóbico, os membros do GHOTA cumpriam o segundo passo da técnica do arco-íris do desejo: eles compartilhavam experiências reais de tal osmose e eram instados a escrever na frente do grupo um script em que a osmose era bloqueada por meio de resistência. Em seguida, eram solicitados a dramatizar o script na frente dos demais. A dramatização visava prepará-los a confrontar seus opressores na vida real - algo que Boal considerava crucial para a destruição do tira na cabeça e, consequentemente, para a eliminação da injustiça epistêmica. "Os tiras estão em suas cabeças, mas os quarteis para os quais trabalham estão na realidade externa. É necessário localizar [e resistir] tanto os tiras [na cabeça] quanto os quarteis para os quais trabalham". ${ }^{44}$

Sarapeck narra a história de Chuchu, jovem que dramatizou perante o grupo uma experiência ruim que teve em uma entrevista de emprego por causa da homofobia do empregador. Familiar com o método de Boal já há algum tempo, Chuchu sabia que sofria injustiça estético-epistêmica. Ele aprendera que a sensação de vergonha que sentia quando sofria homofobia vinha do tira em sua cabeça. Mais ainda, Chuchu percebera que o único jeito de se livrar daquela vergonha era mediante o confronto com a encarnação do tira, que naquela cena específica correspondia ao homem que interpretava o papel do empregador. Na dramatização que realizou na frente do grupo, contudo, Chuchu não conseguiu resistir:

43 Ibid., p. 54.

44 BOAL, A. O arco-íris do desejo, Op. cit., p. 35 e cf. BOAL, A. The Aesthetics of the Oppressed. Londres: Routledge, 2006, p. 5-6. 
Ao som do silêncio da plateia formada exclusivamente por gays, aguardávamos a fala de Chuchu, que marcaria a reação do personagem. Chuchu baixou a cabeça e pensamos: "é agora, ele está lembrando do texto para falar". Erramos. Chuchu estava chorando e rindo ao mesmo tempo. Ainda assim, esperamos mais um, dois minutos, até que, sem saber se fazia o certo, entrei em cena e abracei Chuchu. O espetáculo terminou ali. [...] No meu ouvido, Chuchu declarou: "Eu não posso". ${ }^{45}$

Ao ser recusado de novo o emprego que queria ter, Chuchu foi, como da primeira vez, tomado por uma mistura de tristeza e vergonha. O fato de agora, diferente da primeira vez, acreditar que ser gay não era motivo de vergonha não fez com que, ao fim e ao cabo, ele não sentisse vergonha, motivo por que não conseguiu criar coragem para resistir o empregador homofóbico. Chuchu experimentou o que Fricker chama de "internalização residual", fenômeno que ocorre quando "um membro de um grupo subordinado permanece hospedeiro do que é uma espécie de sobrevida da ideologia opressora, mesmo quando suas crenças sobre o assunto progrediram de maneira genuína". ${ }^{46}$ Fricker sustenta que a internalização residual faz com que os afetos de uma pessoa levem algum tempo para entrar em sintonia com suas crenças epistêmicas. Posto nos termos desse trabalho, a internalização residual é o fenômeno que o oprimido experimenta quando supera a injustiça epistêmica, mas não a estética. A descrição que Fricker oferece para a internalização residual pode ser aplicada ao caso de Chuchu porque, embora não mais acreditasse que a homossexualidade era vergonhosa, Chuchu ainda sentia vergonha quando identificado como homossexual.

A internalização residual mostra que a resistência contra a injustiça epistêmica consegue ser exitosa apenas quando se alia à resistência à injustiça estética. Na medida em que se influenciam mutuamente, a injustiça estética e a injustiça epistêmica precisam ser resistidas em conjunto. Se a injustiça estética permanece, a injustiça epistêmica não tardará a atormentar o oprimido. A injustiça estética propaga-se por modos de imaginação coletivos que inferiorizam alguns grupos ao mesmo tempo em que entronizam outros; a depreciação de alguns e a sobrevalorização de outros são duas faces da mesma moeda. Modos coletivos de se imaginar os diferentes grupos sociais encontram-se profundamente arraigados em nosso aparato estético-cognitivo e enquadram nossas interações com

45 SARAPECK, H. "A descoberta de si mesmo", p. 38.

46 FRICKER, M. Epistemic Injustice, Op. cit., p. 37.

limiar | volume 6 | número 12 | 2. semestre 2019 |117 
outrem de modo quase que automático. ${ }^{47}$ Isto ocorre não porque eles são naturais, mas porque foram reiterados por um longo período. Levou tempo para que eles se enraizassem em nós. Não surpreende, pois, que desvencilhar-se deles também leve tempo.

Examinemos, por exemplo, o caso de Flavio Sanctum, um dos membros mais antigos do GHOTA. O relato pungente de Sanctum de como ele superou sua "autorrepressão" por meio do uso do arco-íris do desejo mostra que a expulsão do tira na cabeça é um processo que demanda tempo. ${ }^{48}$ Mesmo após se livrar da crença de que a homossexualidade era vergonhosa, Sanctum continuava a sentir vergonha ao ser fotografado com os membros do GHOTA. Ou seja: mesmo após superar a injustiça epistêmica, Sanctum continuava a sofrer injustiça estética. Ele conta como costumava esconder seu rosto debaixo de um grande chapéu por ter medo de ser reconhecido por familiares caso a foto fosse publicada em algum jornal. ${ }^{49}$ No entanto, à medida que seu treinamento com o arco-íris do desejo aumentava, seus afetos foram pouco a pouco sincronizados com suas crenças e, hoje em dia, Sanctum não mais sente vergonha de ser identificado como gay. ${ }^{50}$

Resistir à injustiça estético-epistêmica é uma tarefa não apenas intelectual como também afetiva. É por isso que a estética do oprimido, além de encorajar os oprimidos a debater seus problemas coletivamente, exorta-os a produzir imagens afetivas que retratem os sentimentos que têm quando se deparam cara a cara com os opressores. ${ }^{51} \mathrm{~A}$ estética do oprimido consegue, assim, aliar a resistência à injustiça epistêmica à resistência à injustiça estética. Quando as imagens afetivas são dramatizadas, é imprescindível que os oprimidos as escrutinem várias vezes, de modo a orquestrar estratégias subversivas que os ajudem a mudar seus afetos na próxima vez que se depararem com os opressores. Ainda que considere descabido esperar que os afetos sejam postos sob domínio total do sujeito, a técnica do arco-íris do desejo visa fazer com que os oprimidos adquiram algum grau de domínio sobre seus afetos: ao manejar artisticamente as imagens afetivas avivadas pela opressão na frente de outros sujeitos

47 BOAL, A. O arco-íris do desejo, Op. cit. p. 54 e FRICKER, M. Epistemic Injustice, Op. cit. p. 38.

48 SANCTUM, F. "Teatro do oprimido e homossexualidade", p. 20.

49 Ibid., p. 23.

50 Ibid., p. 34.

51 BOAL, A. O arco-íris do desejo, Op. cit., p. 56. 
analogamente oprimidos, o sujeito aprende a alterar, em certa medida, os afetos que servem de veículo promotor da opressão. ${ }^{52}$ A vergonha pode ser transmutada em indignação, e a aquiescência silenciosa, em protesto ruidoso. À medida que ensaiam possíveis estratégias de resistência, os oprimidos conseguem "multiplicar os pontos de vistas possíveis por meio dos quais se pode considerar cada situação". ${ }^{33}$ A multiplicação das perspectivas os permite resistir à opressão por meio da preparação de planos de ação para seus problemas coletivos.

Enfatizamos coletivos no parágrafo anterior para rebater a crítica de que o arco-íris do desejo teria levado a estética do oprimido a negligenciar o aspecto estrutural da opressão e se confundir com uma espécie de terapêutica psicodramática. ${ }^{54}$ Contra essa crítica, Boal enfatiza que as "técnicas do arco-íris do desejo devem fazer parte do estudo de opressões claramente sociais e políticas". ${ }^{55}$ Por isso mesmo, ele recomenda que a utilização do arco-íris do desejo ocorra com sujeitos que enfrentam opressões similares, pois

em uma sessão [...] em que os participantes pertençam ao mesmo grupo social (estudantes de uma mesma escola, moradores de um mesmo bairro, operários de uma mesma fábrica etc.) e sejam submetidos às mesmas opressões (em relação à escola, ao bairro ou à fábrica), o relato individual de uma pessoa se pluralizará imediatamente: a opressão de um deles é a opressão de todos. A particularidade de cada caso individual é negligenciável diante de sua similaridade com todos os outros. Assim, durante a sessão, a sim-patia será imediata. ${ }^{56}$

O arco-íris do desejo encoraja fortemente que os grupos que o praticam componham-se de membros que enfrentam opressões parecidas, pois o objetivo é realçar o aspecto coletivo das opressões sofridas por cada um. ${ }^{57}$ A familiaridade com a opressão alheia faz com que o participante individual sinta-se à vontade quando tem de discutir seus problemas pessoais e, ademais, facilita a construção de estratégias resistentes pelo

52 lbid., p. 77.

53 Ibid., p. 58.

54 Ver DINNEEN, M. "Teatro legislativo: estimulando a ciudadanía ativa" e ÖSTERLIND, E. "Acting out of habits. - can theatre of the oppressed promote change?".

55 BOAL, A. A estética do oprimido, Op. cit., p. 236.

56 BOAL, A. O arco-íris do desejo, Op. cit., p. 58.

57 Como Boal destacara em Teatro do oprimido, "é necessário fazer com que se entenda sempre o caráter genérico do caso particular apresentado" (BOAL, A. Teatro do oprimido, Op. cit., p. 229). O desvelamento do caráter coletivo das forças por detrás de uma opressão individual equivale ao processo que Boal chama de ascese (BOAL, A. A estética do oprimido, Op. cit., p. 189). 
grupo como um todo, o que por sua vez tem o potencial de gerar transformações estruturais na sociedade que minoram a opressão.

O poder que o arco-íris do desejo tem para provocar mudanças estruturais que diminuem a opressão ilustra-se bem no relato de Sanctum. Sanctum afirma que o arco-íris do desejo foi uma técnica indispensável para que os membros do GHOTA conseguissem resistir um restaurante homofóbico do qual vários deles haviam sido expulsos simplesmente por causa de sua sexualidade. ${ }^{58}$ Após alguns debates, os participantes do GHOTA decidiram dramatizar as opressões vivenciadas no estabelecimento "ao ar livre, na porta do restaurante preconceituoso, gerando a participação ativa de todos da plateia". ${ }^{59}$ Terminada a performance, o público presente foi convidado a contribuir para a elaboração "de propostas legislativas" que buscassem evitar que esse tipo de discriminação continuasse a ocorrer nos restaurantes cariocas. ${ }^{60}$ Essas propostas foram posteriormente analisadas "pelos assessores parlamentares e pelo próprio vereador Augusto Boal". ${ }^{61}$ Como resultado, "foi aprovada pela Comissão de Direitos Humanos da ALERJ a lei municipal de número 2475/96, que pune qualquer estabelecimento comercial que discrimine alguém por sua orientação sexual". ${ }^{62}$ Pioneira no país, esta lei foi utilizada alguns anos depois como modelo de uma lei nacional que criminalizou a nível federal a discriminação de clientes em estabelecimentos comerciais por causa de sua orientação sexual. Este exemplo mostra que o arco-íris do desejo tem o potencial de promover a resistência contra a injustiça estética e epistêmica e de gerar mudanças estruturais que mitigam a opressão.

\section{A incompatibilidade entre injustiça estética e democracia}

Enquanto regime em que todos os cidadãos desfrutam de igual liberdade para participar na política, a democracia se opõe à injustiça estética. A sociedade entre iguais que a democracia abrange, diferentemente de regimes opressores que perpetuam injustiça estética, se recusa a segregar os cidadãos em grupos "inferiores" e "superiores".

58 SANCTUM, F. "Teatro do oprimido e homossexualidade", p. 22.

59 Ibidem.

60 Ibidem.

$61 \mathrm{lbidem}$.

62 lbidem. 
A democracia é o regime que legitima e fomenta a multiplicidade estética, ou seja, é o regime no qual os diferentes modos de se perceber e sentir os fenômenos político-sociais são não apenas respeitados como considerados essenciais para a formulação das leis. $A$ democracia requer que todos os cidadãos tenham suas diferentes maneiras de olhar e sentir os assuntos públicos igualmente sopesadas na deliberação política. Ou melhor, requer que os cidadãos aprendam a interagir com a diversidade humana sem tornar a diferença uma razão para a postulação de hierarquias. Em suma, requer justiça estética, prática social que emerge apenas quando a maioria dos cidadãos cessa de encarar a diferença como questão de "ser melhor que" ou "ser pior que". Democracia e justiça estética estão intimamente relacionadas na medida em que ambas se recusam a tratar a diferença como justificativa para a construção de hierarquias. ${ }^{63}$

A democracia é o regime no qual predomina "o respeito e a valorização do indivíduo, todos os indivíduos, com suas opiniões, necessidades e idiossincrasias. Nessa franca liberdade reside a democracia" ${ }^{64}$ Intimamente relacionado a esse respeito à pluralidade humana, consta a convicção de que os problemas políticos sejam analisados "por todos os lados e não por um lado só". 65

Nem todos os olhares veem a mesma coisa. [...] Não existe o olhar puro [...]. É verdade que cada coisa tem dois lados; cada lado, outros lados tem. Postos frente a frente, estabelece-se um jogo de espelhos, e todos os lados se multiplicam ao infinito porque cada lado pode, no espelho, aparecer do outro lado e refletir-se, depois, no próprio lado - pingue-pongue. Substitua agora os lados por opiniões e faça o mesmo raciocínio. ${ }^{66}$

Quando os cidadãos recebem igual liberdade para expressar e trocar suas opiniões em público, as visões políticas se expandem em inúmeras, e por vezes divergentes, direções. Por isso mesmo, aqueles que participam da deliberação democrática tendem a desenvolver uma consciência caleidoscópica, consciência esta que

63 Não surpreende então, como explicaremos em breve, que "democracia", tal qual compreendida nesse texto, designe um modo de existência que ainda não conhecemos. Dado o caráter opressivo de nossas sociedades, somos treinados para automaticamente enquadrar as diferenças entre as pessoas em categorias pré-dadas que reforçam hierarquias sociais opressoras. Como seria experimentar a pluralidade humana sem apelar para tais categorias? Eis a questão que a associação da democracia com a justiça estética nos leva a colocar.

64 BOAL, A. A estética do oprimido, Op. cit., p. 131.

65 Ibid., p. 124.

66 Ibid., p. 31-2, 125. 
os mostra que os assuntos públicos deixam-se interpretar por vários lados. Os diferentes grupos sociais têm diferentes modos de ver os assuntos políticos, e nenhum desses modos deve ser identificado como o olhar "puro" ou "superior" a que todos os demais devem se submeter. Ninguém pode, portanto, selecionar sua perspectiva individual como critério único para a promulgação de uma lei que valerá para todos. Enquanto regime da multiplicidade estética, a democracia exige que as leis sejam elaboradas por meio de um processo deliberativo no qual as opiniões de todos os grupos sociais são igualmente sopesadas. ${ }^{67}$

Boal insiste que não existe uma única maneira correta de se ver e compreender um fenômeno político-estético e explica que nossa compreensão de algo será tão mais completa quanto mais "lados" examinarmos, isto é, quanto mais tomarmos em conta os diferentes modos pelos quais um dado fenômeno se faz sentir e compreender. ${ }^{68} A$ "estética democrática" propugnada por Boal é aquela que, reconhecendo a multiplicidade dos pontos de vista do demos, constantemente instiga os cidadãos a alargarem sua compreensão dos fenômenos estético-políticos e a expandirem sua capacidade de imaginar a sociedade. ${ }^{69}$ Ao fazê-lo, "o fatalismo do beco sem saída, que tantas vezes se instaura em nossas vidas, é substituído pela paleta das opções imaginadas". ${ }^{70}$ A estética democrática - ou o que dá no mesmo, a estética do oprimido - alarga os limites do possível. A democracia tende a maximizar o pensamento crítico dos cidadãos porque, ao deliberarem publicamente e em pé de igualdade, "os oprimidos [conseguem] desenvolver sua capacidade de [...] ver, à distância, a realidade que devem modificar". ${ }^{71}$

Ao permitir que os cidadãos desenvolvam sua imaginação e sintam os assuntos político-sociais de diferentes maneiras, a democracia os permite ocupar diferentes perspectivas, o que por sua vez os confere o poder de criticar a perspectiva atual que

67 Disto não se segue que as decisões políticas em uma democracia tenham que incorporar todas as visões existentes. Para Boal isto seria impossível, não apenas porque as opiniões dos cidadãos podem se contradizer como também porque visões políticas opressivas - i.e., visões que negam a igual liberdade dos cidadãos para se desenvolver - não devem ser incorporadas como base para a formulação de leis. (O que não significa, necessariamente, que os cidadãos não possam expressar em público quaisquer ideias opressoras que possam vir a ter.) De acordo com o pensamento político boalino, um regime democrático que promulgasse leis e decisões baseadas em visões opressivas agiria de modo suicida, pois minaria sua habilidade de se consolidar ao longo do tempo.

68 BOAL, A. A estética do oprimido, Op. cit., p. 125.

69 Ibid., p. 167.

70 lbid., p. 241.

71 lbid., p. 122. 
adotam. Quando o povo oprimido exerce a liberdade de poder desenvolver suas capacidades estéticas e cognitivas mediante o debate público de suas opiniões e perspectivas, ele ganha a oportunidade de se descolar da narrativa hegemônica ditada pelo opressor (a qual até então aderira irrefletidamente). Com isso, consegue discernir "opressões desapercebidas: é preciso desfamiliarizar a opressão para que se possa vê-la e combatê-la". ${ }^{72} \mathrm{O}$ primeiro passo para se resistir a injustiça estética e lutar contra a opressão é perceber que se é oprimido. Ao estimular os cidadãos a "ver o que olham, e não apenas sobrevoar realidades sem senti-las", a estética democrática boalina ajuda o oprimido a dar esse primeiro passo. ${ }^{73}$

Quando os cidadãos oprimidos resistem à injustiça estética, eles adquirem as capacidades de criticar e julgar a perspectiva ditada pelo opressor e de imaginar a existência coletiva sob um novo modo. Criando novos campos de percepção estética, eles rompem com a partilha hegemônica do que pode e do que não pode ser sentido e aprendem que a transformação social é possível. ${ }^{74}$ Mais do que qualquer outro regime, a democracia realça o caráter histórico da política: artifício humano que é, o mundo político pode ser transformado para melhor se uma quantidade suficiente de pessoas agir com tal intuito. Semelhante encorajamento para a ação transformadora diferencia a democracia de regimes opressores que propagam a resignação e a apatia popular por meio da atrofia das capacidades estéticas do povo. A democracia torna-se impossível quando os opressores monopolizam a produção de imagens e palavras - a saber, os dois principais veículos de expressão estética - a fim de embotar a capacidade dos oprimidos de conhecer e sentir a realidade. Quando a capacidade dos cidadãos de imaginar e sentir a existência política é propositalmente coarctada e restrita a limites estreitos, uma das paixões primaciais da base afetiva que sustém a democracia - qual seja, a paixão pela abertura $^{75}$ - esvanece.

72 lbid., p. 189.

73 Ibid., p. 201.

74 Conforme apontam alguns comentadores, a estética do oprimido boalina promove a democracia e combate a opressão através de uma reconfiguração daquilo que Jacques Rancière chama de "partilha do sensível". Cf. COUDRAY, S. "Le théâtre de l'opprimé"; GOMES, P. A. B. C. e GODAR, J. O. "A emancipação pedagógica de Jacques Rancière e o teatro do oprimido como re-partilha do sensível"; SHAWYER, S. "Emancipated spect-actors: Boal, Rancière, and the twenty-first century spectator".

75 FERRARA, A. The Democratic Horizon. Cambridge: Cambridge University Press, 2014, cap. 2. 
$\mathrm{Na}$ esteira de Boal, empregamos o termo "democracia" para denotar não apenas uma forma de governo na qual os governantes são eleitos pelo voto popular, mas também uma forma de sociedade em que todos os cidadãos têm oportunidade para se desenvolver. Longe de designar simplesmente um procedimento "neutro" que permite a sucessão de diferentes governos sem derramamento de sangue, "democracia" expressa, aqui, um modo de organizar a existência coletiva que confere a cada um os recursos necessários para o desenvolvimento de si - vale dizer, para o processo de florescimento humano que só é possível mediante cultivo das capacidades estéticas e epistêmicas do ser humano.

"Democracia", aqui, não é um termo descritivo que expressa uma realidade prévia da qual desfrutamos. Antes, é um termo normativo que contém parâmetros que nos ajudam a democratizar as sociedades em que vivemos. Tal qual Boal, entendemos que ainda não vivemos em "uma democracia real", pois esta só emergirá quando todos os cidadãos e cidadãs tiverem "condições e meios para desenvolver suas potencialidades em todas as direções" ${ }^{76}$ Uma sociedade democrática consolidar-se-á apenas com cidadãos e cidadãs que são capazes de sentir e conhecer a realidade circundante de maneira plena e que, portanto, conseguem realizar escolhas conscientes e resistir à opressão.

Empregamos na frase anterior o verbo resistir, e não superar, porque para Boal a opressão e a injustiça epistêmica dela resultante não são passíveis de serem eliminadas de uma vez por todas. Na vida coletiva, a opressão de um ou outro grupo sobre outros grupos sociais cedo ou tarde acaba se manifestando. É por ter ciência do caráter inextirpável da opressão que Boal defende a democracia. O regime democrático é melhor que os outros não porque elimina de vez a opressão, mas sim porque, ao dar visibilidade e problematizar as exclusões existentes, oferece recursos para que as mesmas sejam contestadas e minoradas.

O poder que a contestação popular tem para minorar a opressão, contudo, não se concretiza quando a injustiça estética é onipresente. A injustiça estética é inimiga da democracia porque, ao constranger a capacidade dos cidadãos de pensar e imaginar a existência coletiva sob diferentes modos, ela torna difícil o cultivo de atitudes conducentes

76 BOAL, A. A estética do oprimido, Op. cit., p. 169. 
a um ethos democrático, tais quais a abertura à diferença e o falibilismo. Mais do que uma forma de governo, a democracia é uma forma social que infunde nos cidadãos um tipo específico de "caráter" ou "ethos". ${ }^{77}$ Diferentes tipos de regime fomentam diferentes tipos de subjetividade. Ao passo que em regimes opressores autoritários a tendência é encontrar indivíduos acríticos e dogmáticos, na democracia os cidadãos desenvolvem uma disposição para o pensamento crítico e constantemente escrutinam suas convicções políticas.

A democracia maximiza o desenvolvimento humano porque põe a nu a "multiplicidade" constitutiva tanto da sociedade quanto do indivíduo. ${ }^{78}$ Enquanto prática de resistência à injustiça estética, a democracia destaca o fato de cada um de nós abrigar dentro de si "identidades em desuso" ${ }^{79}$ Visto diminuir a injustiça estética, o exercício da democracia leva os cidadãos a descobrir e desenvolver a pluralidade de caracteres que possuem dentro de si, o que por sua vez faz com que eles expandam sua individualidade. A injustiça estética desumaniza os cidadãos porque asfixia a atualização da pluralidade interna que singulariza cada ser humano.

\section{Considerações finais}

O objetivo deste artigo foi apresentar o conceito de injustiça estética, que denota todo dano causado a alguém especificamente no que tange suas capacidades estéticas. O tipo de opressão demarcado por este conceito precisa ser investigado pelos filósofos políticos contemporâneos que estudam a opressão causada pela injustiça epistêmica. Visto que ambos os tipos de injustiça se retroalimentam, a desatenção dos filósofos no que tange à injustiça estética pode ser considerada uma falha grave. Afinal, se uma grande parte deles estuda a injustiça epistêmica com o objetivo de apontar possíveis maneiras de resisti-la, cabe-Ihes, a fim de cumprir semelhante objetivo, estudar também a injustiça estética. Filósofos e teóricos políticos, em suma, devem perquirir os mecanismos pelos quais a injustiça estética promove a injustiça epistêmica e o meio pelo qual a opressão resultante de ambos os tipos de injustiça obstrui a democracia.

77 lbid., p. 229, 246.

78 Ibid., p. 199.

79 Ibidem. 
gustavo hessmann dalaqua - injustiça estética

\section{Referências bibliográficas}

AUSLANDER, Phillip. "Boal, Blau, Brecht: the body". In SCHUTZMAN, Mady; COHENCRUZ, Jan (Eds.). Playing Boal. London: Routledge, 2002, p. 134-143.

BARTKY, Sandra Lee. Femininity and Domination: Studies in the Phenomenology of Oppression. London: Routledge, 1990.

BHARGAVA, Rajeev. "Overcoming the epistemic injustice of colonialism". Global Policy, v. 4, n. 4, p. 413-417, 2013.

BINZER, Ina von. Os meus romanos: alegrias e tristezas de uma educadora alemã no Brasil. Rio de Janeiro: Editora Paz e Terra, 1994.

BOAL, Augusto. Técnicas latino-americanas de teatro popular: uma revolução copernicana ao contrário. São Paulo: Hucitec, 1984.

BOAL, Augusto. Aqui ninguém é burro! Rio de Janeiro: Revan, 1996a.

BOAL, Augusto. O arco-íris do desejo: método Boal de teatro e terapia. Rio de Janeiro: Editora Record, 1996b.

BOAL, Augusto. 200 exercícios e jogos para o ator e o não-ator com vontade de dizer algo através do teatro. Rio de Janeiro: Civilização Brasileira, 1999a.

BOAL, Augusto. Jogos para atores e não-atores. Rio de Janeiro: Civilização Brasileira, $1999 b$.

BOAL, Augusto. Teatro do oprimido e outras poéticas políticas. Rio de Janeiro: Civilização Brasileira, 2005.

BOAL, Augusto. The Aesthetics of the Oppressed. Trans. A. Jackson. London: Routledge, 2006.

BOAL, Augusto. A estética do oprimido. Rio de Janeiro: Garamond, 2009.

BOAL, Augusto; EPSTEIN, Susana. "The cop in the head: three hypotheses". TDR (1988-), v. 34, n. 3, p. 35-42, 1990.

CABRAL, Amilcar. Return to the Source: Selected Speeches by Amilcar Cabral. New York: Monthly Review Press, 1973.

CABRAL, Amílcar. A prática revolucionária: unidade e luta II. Lisboa: Seara Nova, 1977. 
COUDRAY, Sophie. "Le théâtre de l'opprimé. Quelles perspectives émancipatrices pour un théâtre d'éducation populaire ?" Recherches \& Éducations, n. 16, p. 65-77, 2016.

CUDD, Ann E. Analyzing Oppression. Oxford: Oxford University Press, 2006.

DE LEÓN, Jennifer Ponce; ROCKHILL, Gabriel. "Toward a compositional model of ideology: materialism, aesthetics \& cultural revolution". Philosophy Today, no prelo.

DINNEEN, Mark. "Teatro legislativo: estimulando a ciudadanía ativa". Teatro: Revista de Estudios Culturales / A Journal of Cultural Studies, n. 26, p. 141-161, 2013.

FERRARA, Alessandro. The Democratic Horizon: Hyperpluralism and the Renewal of Political Liberalism. Cambridge: Cambridge University Press, 2014.

FISHER, Tony. "Radical democratic theatre". Performance Research, v. 16, n. 4, p. 15-26, 2011.

FOUCAULT, Michel. Histoire de la sexualité, tome I. Paris: Gallimard, 1976.

FREIRE, Paulo. Pedagogia do oprimido. Rio de Janeiro: Editora Paz e Terra, 1974.

FREIRE, Paulo. Cartas a Cristina. Rio de Janeiro: Editora Paz e Terra, 1994.

FRICKER, Miranda. Epistemic Injustice: Power and the Ethics of Knowing. Oxford: Oxford University Press, 2007.

GIBSON, Nigel C. "No easy victories: some reflections on Amilcar Cabral's legacy". In MANJI, Firoze; FLETCHER, Bill (Eds.). Claim No Easy Victories: The Legacy of Amilcar Cabral. Dakar: CODESRIA/Daraja Press, 2013, p. 17-30.

GOMES, Pedro Augusto Boal Costa; DE OLIVEIRA GONDAR, Josaida. "A emancipação pedagógica de Jacques Rancière e o Teatro do Oprimido como re-partilha do sensível". INTERthesis: Revista Internacional Interdisciplinar, v. 12, n. 1, p. 192-208, 2015. HOWE, Kelly. "Constraints and possibilities in the flesh: the body in theatre of the oppressed". In HOWE, Kelly; BOAL, Julian; SOEIRO, José (Eds.). The Routledge Companion to Theatre of the Oppressed. London: Routledge, 2019, p. 76-85.

KIDD, lan James; MEDINA, José; POHLHAUS Jr., Gaile (Eds.). The Routledge Handbook of Epistemic Injustice. London: Routledge, 2017.

LEAL, Dodi. Pedagogia e estética do teatro do oprimido: marcas da arte teatral na gestão pública. São Paulo: Hucitec, 2015.

MEMMI, Albert. Retrato do colonizado precedido pelo retrato do colonizador. Trad. R. Corbisier e M. P. Coelho. Rio de Janeiro: Paz e Terra, 1967. 
gustavo hessmann dalaqua - injustiça estética

MILLS, Charles W. "Ideology". In KIDD, Ian James; MEDINA, José; POHLHAUS Jr., Gaile (Eds.). The Routledge Handbook of Epistemic Injustice. London: Routledge, 2017, p. 100111.

MORRISON, Toni. The Origin of Others. Cambridge, MA: Harvard University Press, 2017. MUTNICK, Deborah. "Critical interventions: the meaning of praxis". In COHEN-CRUZ, Jan; SCHUTZMAN, Mady (Eds.). A Boal Companion: Dialogues on Theatre and Cultural Politics. London: Routledge, 2006, p. 33-45.

ÖSTERLIND, Eva. "Acting out of habits - can theatre of the oppressed promote change? Boal's theatre methods in relation to Bordieu's concept of habitus". Research in Drama Education, v. 13, n. 1, p. 71-82, 2008.

PATERSON, Doug. "Putting the 'pro' in protagonist: Paulo Freire's contribution to our understanding of forum theatre". In EMERT, Toby; FRIEDLAND Ellie (Eds.). "Come Closer." Critical Perspectives on Theatre of the Oppressed. New York: Peter Lang, 2011, p. 9-20.

RABAKA, Reiland. Africana Critical Theory: Reconstructing the Black Radical Tradition, from W. E. B. Du Bois and C. L. R. James to Frantz Fanon and Amilcar Cabral. Lanham, MD: Lexington Books, 2009.

RABAKA, Reiland. Concepts of Cabralism: Amilcar Cabral and Africana Critical Theory. Lanham, MD: Lexington Books, 2014.

RATNER, Carl. "Psychology of oppression". In TEO, Thomas (Ed.). Encyclopedia of Critical Psychology. New York: Springer, 2014, p. 1557-1570.

SANCTUM, Flavio. "Teatro do oprimido e homossexualidade: um arco-íris em construção". In SANCTUM, Flavio; SARAPECK, Helen (Eds.). Teatro do oprimido e outros babados: a diversidade sexual em cena. Rio de Janeiro: Metanoia, 2015, p. 18-35.

SANTOS, Boaventura de Sousa. O fim do império cognitivo: a afirmação das epistemologias do Sul. Belo Horizonte: Autêntica, 2019.

SARAPECK, Helen. "A descoberta de si mesmo". In SANCTUM, Flavio; SARAPECK, Helen (Eds.). Teatro do oprimido e outros babados: a diversidade sexual em cena. Rio de Janeiro: Metanoia, 2015, p. 36-40.

SCHECHNER, Richard; CHATTERJEE, Sudipto. "Augusto Boal, city councillor: legislative theatre and the chamber in the streets". TDR (1988-), v. 42, n. 4, p. 75-90, 1998. 
SHAWYER, Susanne. "Emancipated spect-actors: Boal, Rancière, and the twenty-first century spectator". Performance Matters, v. 5, n. 2, p. 41-54, 2019.

VITTORIA, Paolo. "Paulo Freire and Augusto Boal: praxis, poetry, and utopia". In HOWE, Kelly; BOAL, Julian; SOEIRO, José (Eds.). The Routledge Companion to Theatre of the Oppressed. London: Routledge, 2019, p. 58-65.

YOUNG, Iris Marion. Justice and the Politics of Difference. Princeton, NJ: Princeton University Press, 1990. 